\title{
A Systematic Review of the Clinical Utility of Cycle Threshold Values in the Context of COVID-19
}

Sonia N. Rao · Davide Manissero • Victoria R. Steele · Josep Pareja

\section{ABSTRACT}

Background: The ability to predict likely prognosis and infectiousness for patients with COVID-19 would aid patient management decisions. Diagnosis is usually via real-time PCR, and it is unclear whether the semi-quantitative capability of this method, determining viral load through cycle threshold $(\mathrm{Ct})$ values, can be leveraged.

Objectives: We aim to review available knowledge on correlations between SARS-COV-2 Ct values and patient- or healthcare-related

Digital Features: To view digital features for this article go to https://doi.org/10.6084/m9.figshare.12668408.

Electronic supplementary material The online version of this article (https://doi.org/10.1007/s40121020-00324-3) contains supplementary material, which is available to authorized users.

S. N. Rao

QIAGEN Inc, Germantown, MD, USA

D. Manissero

QIAGEN Manchester Ltd, Manchester, UK

V. R. Steele

Ashfield Healthcare Communications, Macclesfield, UK

J. Pareja $(\bowtie)$

STAT-Dx Life, S.L. (a QIAGEN Company), Barcelona, Spain

e-mail: josep.pareja@qiagen.com outcomes to determine whether Ct values provide useful clinical information.

Sources: A PubMed search was conducted on 1 June 2020 based on a search strategy of (Ct value OR viral load) AND SARS-CoV-2. Data were extracted from studies reporting on the presence or absence of an association between $\mathrm{Ct}$ values, or viral loads determined via $\mathrm{Ct}$ value, and clinical outcomes.

Content: Data from 18 studies were relevant for inclusion. One study reported on the correlation between $\mathrm{Ct}$ values and mortality and one study reported on the correlation between $\mathrm{Ct}$ values and progression to severe disease; both reported a significant association $(p<0.001$ and $p=0.008$, respectively). Fourteen studies reported on the correlation between Ct value or viral loads determined via $\mathrm{Ct}$ value and disease severity, and an association was observed in eight (57\%) studies. Studies reporting on the correlation of viral load with biochemical and haematological markers showed an association with at least one marker, including increased lactate dehydrogenase $(n=4)$, decreased lymphocytes $(n=3)$ and increased high-sensitivity troponin I $(n=2)$. Two studies reporting on the correlation with infectivity showed that lower $\mathrm{Ct}$ values were associated with higher viral culture positivity.

Implications: Data suggest that lower Ct values may be associated with worse outcomes and that $\mathrm{Ct}$ values may be useful in predicting the clinical course and prognosis of patients with 
COVID-19; however, further studies are warranted to confirm clinical value.

Keywords: COVID-19; Cycle threshold; PCR; SARS-CoV-2; Viral load

\section{Key Summary Points}

Systematic literature review to understand whether SARS-CoV-2 cycle threshold (Ct) values correlate with clinical outcomes and therefore whether they could provide valuable information to clinicians as patients infected with SARS-CoV-2 display disparate disease severity.

The results of this review indicate that lower $\mathrm{Ct}$ values are potentially associated with worse outcomes in COVID-19 patients.

Low SARS-CoV-2 Ct values correlate with increased probability of progression to severe disease, increased disease severity, increased mortality and presence of biochemical and haematological markers.

While reporting of qualitative SARS-CoV-2 test results as positive or negative is sufficient for diagnosis, the reporting of $\mathrm{Ct}$ values may offer benefit to clinicians in making clinical and patient-management decisions for patients with COVID-19 as well as guide infection control, public health and occupational health decisions.

\section{INTRODUCTION}

Patients infected with severe acute respiratory syndrome coronavirus 2 (SARS-CoV-2) display disparate disease severity, ranging from an absence of symptoms to requiring intensive care and fatal outcomes [1]. Therefore, the ability to predict the likely prognosis and infectiousness of patients at diagnosis would greatly aid treatment and patient management decisions.
The standard molecular method for coronavirus disease 2019 (COVID-19) diagnosis is via real-time reverse transcription polymerase chain reaction (RT-PCR) [2]. Real-time RT-PCR cycle threshold $(\mathrm{Ct})$ values represent the number of amplification cycles required for the target gene to exceed a threshold level. Ct values are therefore inversely related to viral load and can provide an indirect method of quantifying the copy number of viral RNA in the sample; however, the use of $\mathrm{Ct}$ values as a proxy of viral load is influenced by the assay itself (correlation would stand in the linear dynamic range of the specific RT-PCR assay used) and factors within the sample matrix that can affect amplification efficiency [3].

It has previously been suggested that the viral load of SARS-CoV-2 may be an important factor in determining both disease severity and likelihood of transmission [4-6]. Although there are many differences between the current SARSCoV-2 pandemic compared to the SARS-CoV epidemic of 2002, evidence from SARS-CoV indicated that higher viral load was associated with increased need for intensive care and overall worse prognosis [7-9]. In a clinical setting, the results of SARS-CoV-2 RT-PCR diagnostic tests are usually reported qualitatively as a binary positive or negative result using a specified cut-off, either based on Ct or integrated by an automatic algorithm interpreting different parameters of the potential amplification; $\mathrm{Ct}$ values themselves are not normally reported. It is currently unclear whether SARSCoV-2 Ct values could be leveraged to guide patient management decisions.

In this review, we assessed the available global literature to determine whether there is evidence that SARS-CoV-2 Ct values correlate with clinical outcomes and therefore whether they could provide valuable information to clinicians for more tailored decision-making.

\section{METHODS}

This review was undertaken according to the principles outlined in the Cochrane handbook. A comprehensive search of PubMed was conducted on 1 June 2020 based on the following 
search strategy: (Ct value OR viral load) AND SARS-CoV-2. The full search string is presented in the Supplementary Materials. Titles and abstracts were screened for relevance by two independent reviewers, and a third reviewer resolved conflicts. All studies that were conducted in humans diagnosed with COVID-19 and reported on the presence or absence of an association between real-time RT-PCR Ct values, or viral load specifically determined via realtime PCR Ct value, and clinical or healthcareassociated outcomes were eligible for inclusion. Studies that reported only on the time course of SARS-CoV-2 viral load or that only compared viral load in different sample types or using different methodologies were not included. Prereview articles, animal studies and reviews were excluded, but additional publications were identified by manual citation searching of appropriate reviews. The full texts of relevant studies were assessed for inclusion by two independent reviewers and key data from all included studies were captured using a data extraction form. All extracted data were verified by an independent reviewer. This article is based on previously conducted studies and does not contain any studies with human participants or animals performed by any of the authors.

\section{RESULTS}

\section{Included Studies}

PubMed searches identified 162 unique records for screening and one study was identified through manual citation searches. The PRISMA flowchart of included studies is shown in Fig. 1. Data from 18 studies were relevant for inclusion and are summarised in Tables 1 and 2 .

Twelve studies (63\%) were conducted in China or Hong Kong [10-21], three studies were performed in Europe [22-24] and three studies were carried out in the USA or Canada [25-27]. Nearly all studies reported data for specimens from the respiratory tract, although two studies analysed saliva [21, 22], one used stool and serum samples in addition to respiratory samples [19], and one used both throat and anal swabs [18]. The real-time PCR targets varied between studies and included ORF1ab (including RdRp), $\mathrm{N}$ and $\mathrm{E}$ genes and the $5^{\prime}$ untranslated genome region. Six studies analysed SARSCoV-2 Ct values at multiple time points for each patient [10, 11, 18-21], and seven studies determined $\mathrm{Ct}$ values at hospital admission or diagnosis [12-17, 22]. Fourteen studies reported on the direct correlation of outcomes with $\mathrm{Ct}$ values [10-14, 16, 17, 20, 22-27]. Three studies reported on the correlation of outcomes with viral load, determined using standard curves of Ct values versus RNA copy number $[15,19,21]$, and one study correlated outcomes with the inverse of $\mathrm{Ct}$ values, taken as a proxy for viral load [18].

\section{Mortality}

Only one study reported on the correlation between SARS-CoV-2 Ct values and mortality (Table 1). In 308 hospitalised adult patients in China, average Ct values across multiple time points during the disease course were lower in patients who died compared with those who had recovered or who were still hospitalised at the end of the study (recovered: median 37.43 [interquartile range (IQR) 34.94-38.67]; still hospitalised: median 36.97 [IQR 34.33-38.70]; deceased: median 34.79 [IQR 24.46-37.65]; $p<0.001)$ [11].

\section{Disease Progression}

One study reported that SARS-CoV-2 Ct values at hospital admission negatively correlated with the probability of progression to severe disease in 62 patients who presented with mild-moderate disease (Table 1) [17]. Lower Ct values were observed in specimens from patients who became severely ill during hospitalisation than in those who did not ( 24 vs. $29 ; p=0.008$ ).

\section{Disease Severity}

Eleven studies (with numbers of PCR-positive patients ranging from 10 to 308) reported on the correlation between $\mathrm{Ct}$ value and disease 

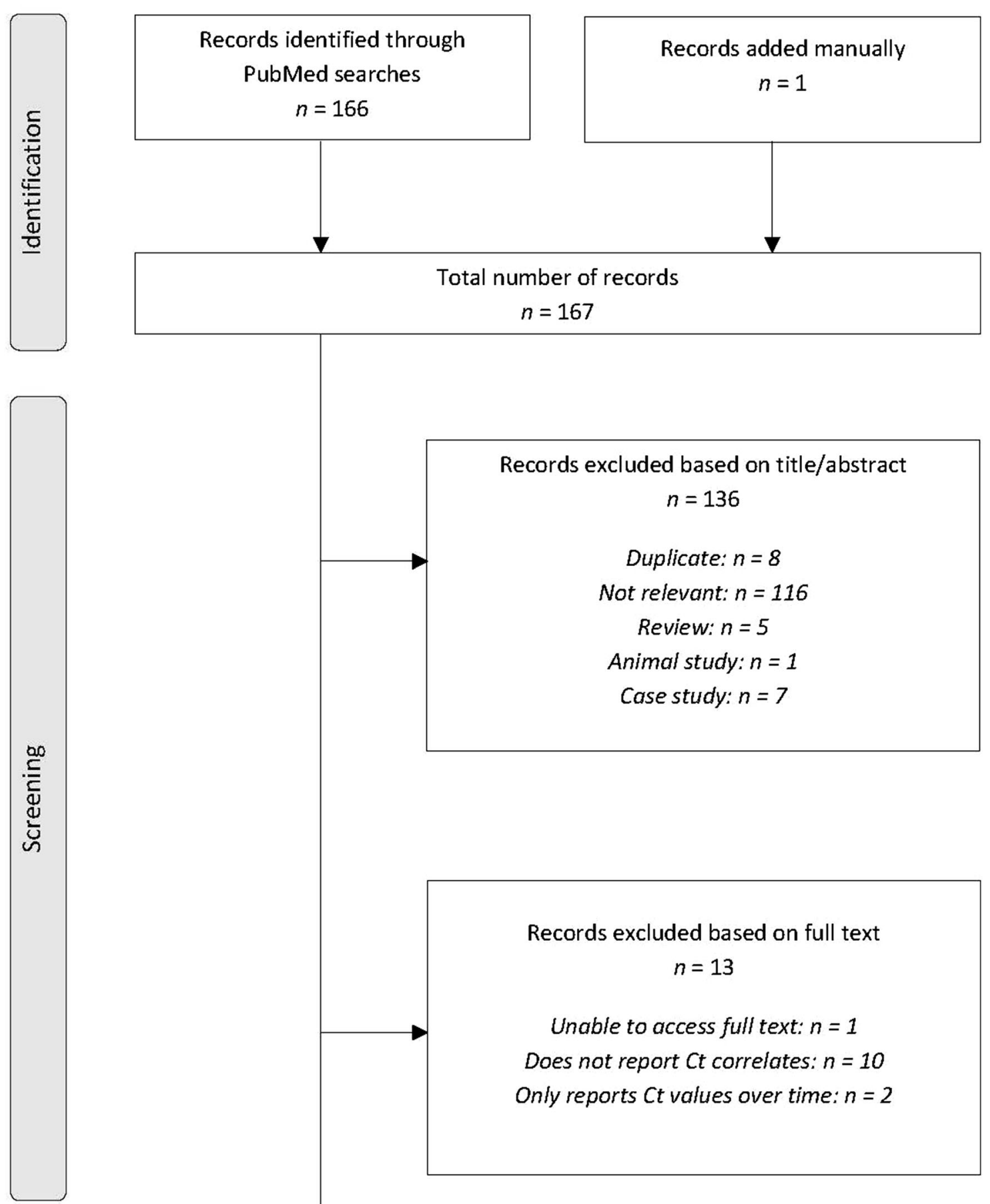

Records excluded based on title/abstract

$$
n=136
$$

Duplicate: $n=8$

Not relevant: $n=116$

Review: $n=5$

Animal study: $n=1$

Case study: $n=7$

Records excluded based on full text

$$
n=13
$$

Unable to access full text: $n=1$

Does not report Ct correlates: $n=10$

Only reports Ct values over time: $n=2$

Included studies

$n=18$ 
Fig. 1 PRISMA flow diagram

severity $[10-14,16,17,20,23,25,26]$ and lower Ct values from respiratory samples were associated with more severe disease in seven (64\%) of these (Table 2) [11-14, 16, 17, 23]. Three studies (with numbers of PCR-positive patients ranging from 23 to 114) reported on the correlation between viral load determined via $\mathrm{Ct}$ values and disease severity $[15,19,21]$ and one of these (which included 96 patients) reported that higher viral loads were significantly associated with more severe disease (Table 2) [19]. In a study by Shi et al., mean viral loads were not significantly different between patients with pneumonia, severe pneumonia and without pneumonia, but in two subgroups analysed (female subgroup and C-reactive protein- and serum amyloid A-positive subgroup), a significantly higher viral load was observed in patients with severe pneumonia compared with those without pneumonia [15].

Of the 15 studies reporting on the correlation between $\mathrm{Ct}$ value or viral load determined via $\mathrm{Ct}$ value and disease severity, 11 were performed in hospitalised patients $[10-17,19,21,23]$ and three included nonhospitalised patients $[20,25,26]$. Of the eleven studies performed in hospitalised patients only, eight (73\%) reported an association between Ct value and disease severity [11-14, 16, 17, 19, 23], of which six showed statistical significance $[12-14,17,19,23]$. None of three studies that included non-hospitalised patients reported that patients with severe disease had higher viral loads compared with those with mild disease $[20,25,26]$.

\section{Biochemical and Haematological Markers}

All five studies (with numbers of PCR-positive patients ranging from 12 to 308) reporting on the correlation of $\mathrm{Ct}$ value with biochemical and haematological markers showed a correlation with at least one marker (Table 2) $[11,13,14,18,22]$. Lower Ct values were significantly associated with: higher lactate dehydrogenase (LDH) levels $(n=4)$ $[11,13,18,22]$; lower lymphocyte counts and/ or percentages $(n=3)[11,13,14]$; lower T-cell counts $(n=3)[11,13,18]$; lower serum albumin levels $(n=2)[11,14]$; increased levels of creatinine kinase myocardial band $(n=2)[11,18]$; increased levels of high-sensitivity troponin 1 $(n=2)[11,13]$. Two studies showed that lower Ct values were associated with higher neutrophil counts and/or percentages [11, 14], whereas one study showed a negative correlation [18]. One study in 12 patients showed that C-reactive protein levels negatively correlated with Ct value $(r=-0.584 ; p=0.03)$ [14], whereas another in 25 patients showed no significant association ( $p=0.07)$ [22]. Associations were also reported between $\mathrm{Ct}$ values and angiotensin II [14], IL-2R [13], basophil and eosinophil counts as well as levels of myoglobin, N-terminal pro-brain natriuretic peptide, inorganic phosphorus and calcium [11].

\section{Infectivity}

Two studies reported on the correlation between Ct value and infectivity and showed that lower $\mathrm{Ct}$ values were associated with higher probability of a positive viral culture (Table 2) $[24,27]$. In one study of 155 patients, multivariate logistic regression analyses using time from symptom onset to test, age and gender as independent variables showed a significant effect of $\mathrm{Ct}$ value on the culture positivity of samples [OR 0.64 (95\% confidence interval $0.49,0.84), p<0.001]$ suggesting that for every one unit increase in $\mathrm{Ct}$, the odds of positive culture decreased by $32 \%$ [27]. The results demonstrated that infectivity (defined as growth in cell culture) was significantly reduced when RT-PCR Ct values were $>24(p<0.001)$.

\section{DISCUSSION}

The majority of the 18 studies identified in this review reported an association between SARS$\mathrm{CoV}-2 \mathrm{Ct}$ values or viral load determined via $\mathrm{Ct}$ values and clinical outcomes. Higher $\mathrm{Ct}$ values generally correlate with lower viral loads, although Ct value and log viral load may not be 


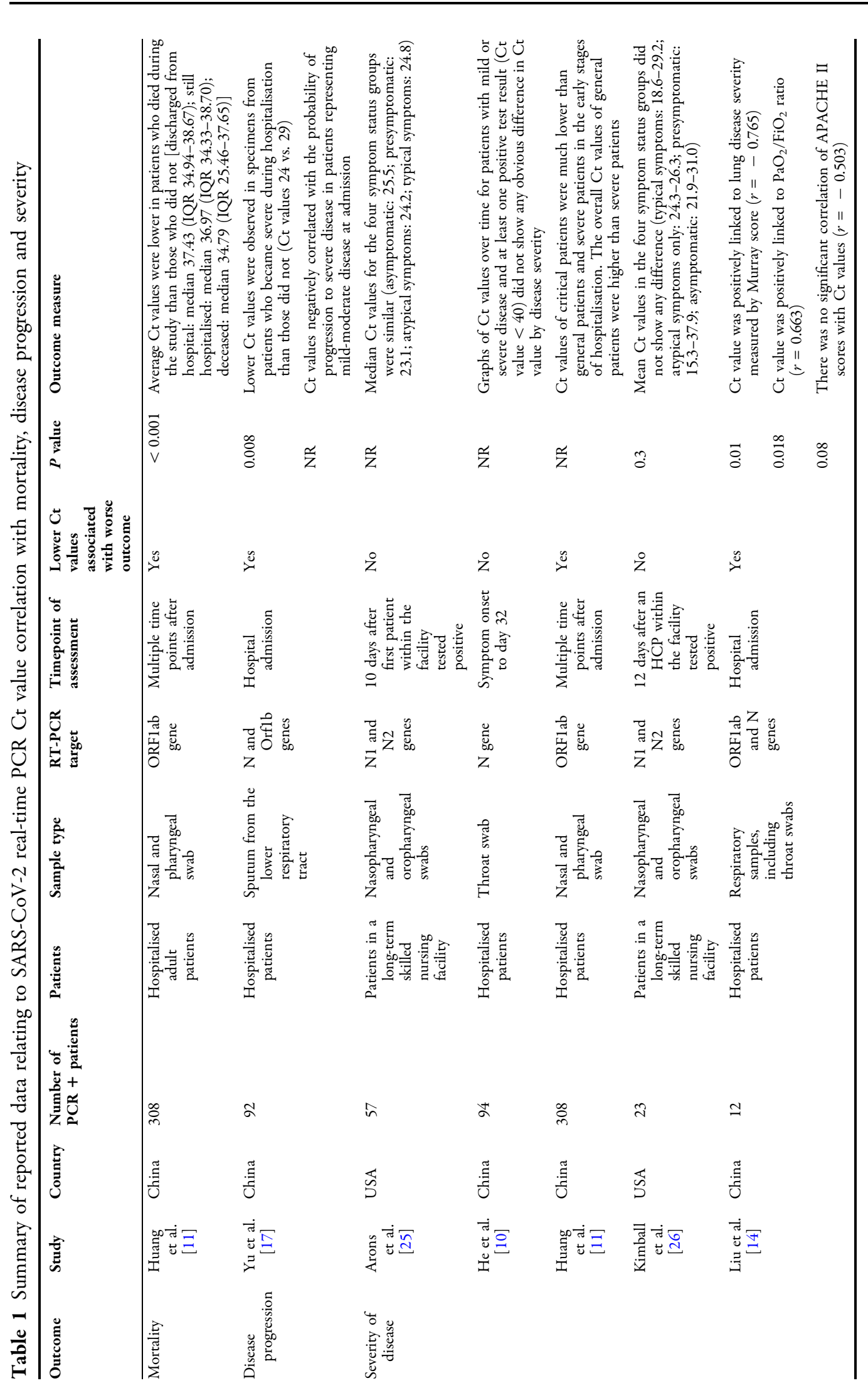




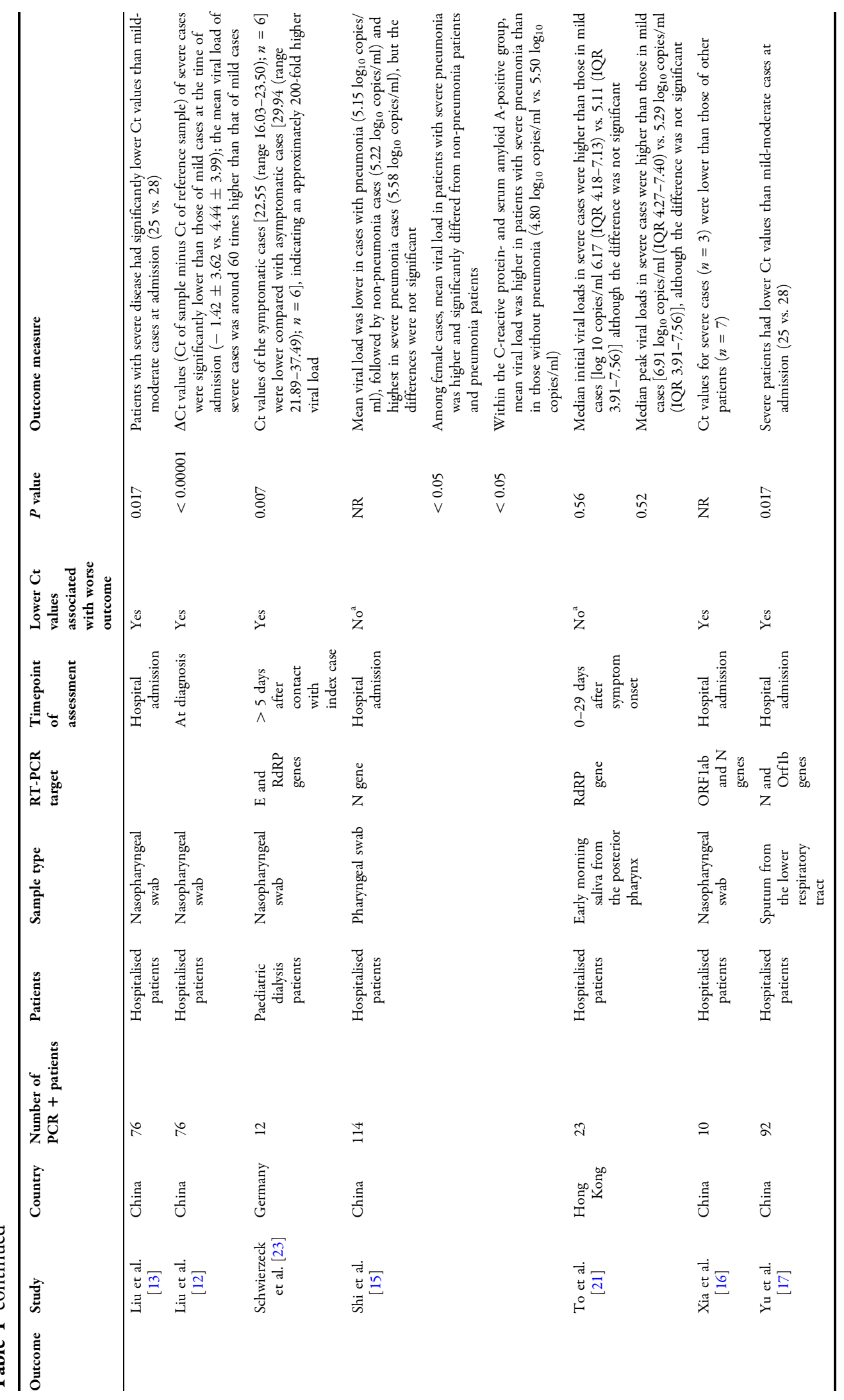




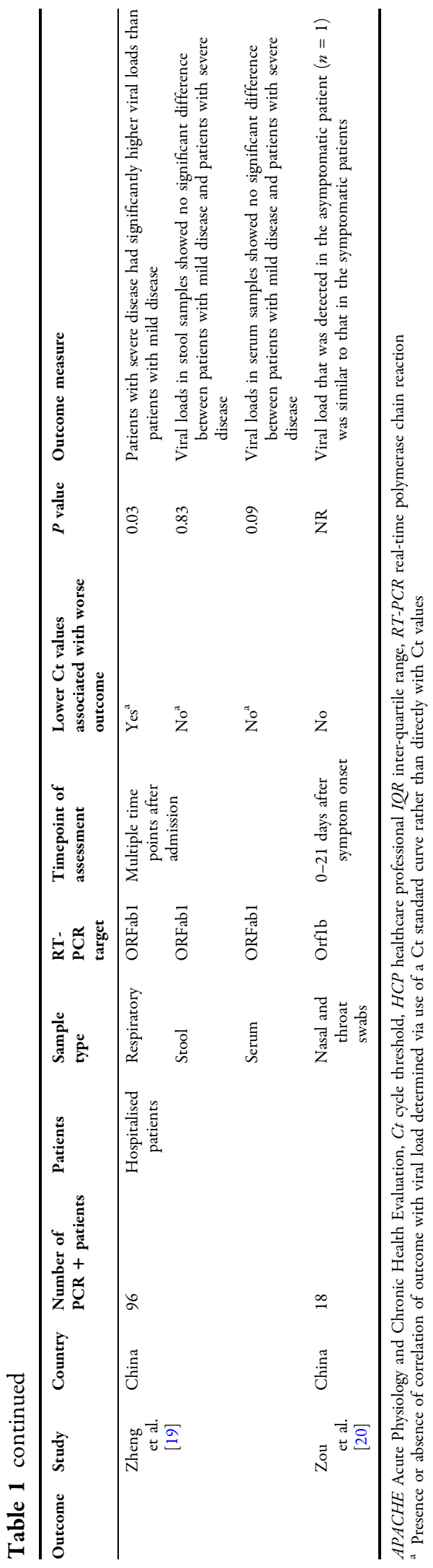

directly proportional because of the linear dynamic range of the assay and potential presence of inhibitory factors within clinical samples [28]. Fifteen (79\%) of the studies included in this review investigated the direct association of $\mathrm{Ct}$ values with clinical outcomes rather than viral load itself, but it was assumed by authors that $\mathrm{Ct}$ values are an appropriate surrogate for viral load.

Clinical knowledge of COVID-19 is constantly evolving, with studies being published at a high rate; however, there are currently only limited data relating to the correlation of viral loads with patient prognoses, such as mortality or disease progression. Only one study reported on the association between mortality and SARSCov-2 Ct value and showed that lower Ct values correlated with increased risk of death [11], which is consistent with data for previous epidemic-causing coronaviruses [9, 29]. Given the wide range in disease course for COVID-19, the ability to predict which patients are at particularly high risk of deterioration and negative outcomes would be of particular value in the clinical setting; it would therefore be useful to continue to assess the value of SARS-CoV-2 Ct as further data become available.

Eleven studies reported on the correlation of Ct values with symptom severity at presentation and seven of these indicated that lower $\mathrm{Ct}$ values were associated with more severe disease. This is consistent with some previous studies of $\mathrm{Ct}$ values in other respiratory infections [29-31], although other studies do not show correlation [32]. Whilst correlation between Ct value and disease severity was observed for 73\% of studies in hospitalised patients, correlation between $\mathrm{Ct}$ or viral load determined via $\mathrm{Ct}$ value and disease severity was observed in none of the studies that included patients with COVID-19 who were not hospitalised. Studies in hospitalised patients are unlikely to include asymptomatic patients or those with very mild symptoms, but are likely to be more controlled, making correlations with $\mathrm{Ct}$ more probable. The role that symptoms play in viral shedding remains to be determined; in a large study of 5830 patients with COVID-19, which was prereview at the time that this review was conducted, viral load determined via $\mathrm{Ct}$ values in 


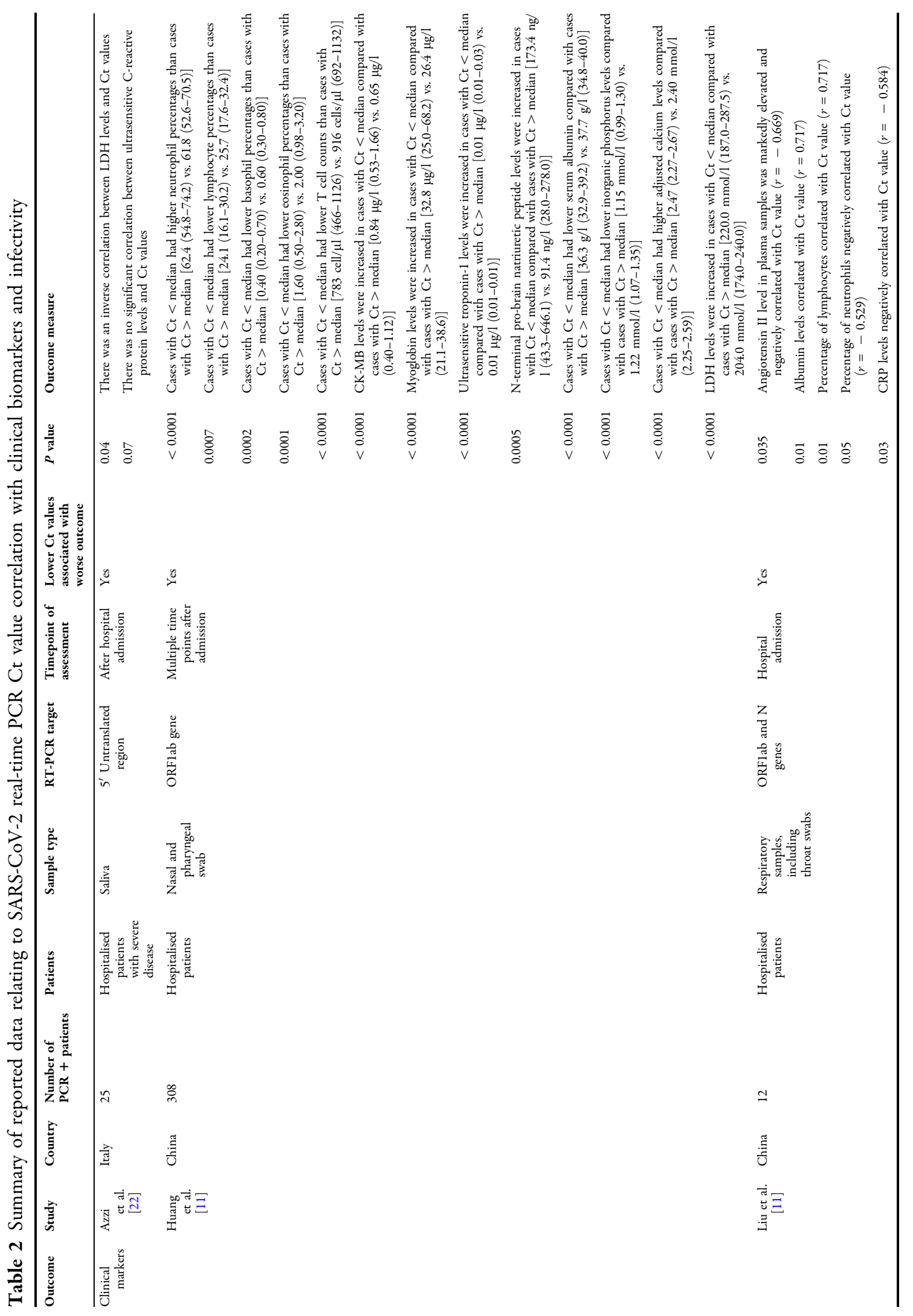




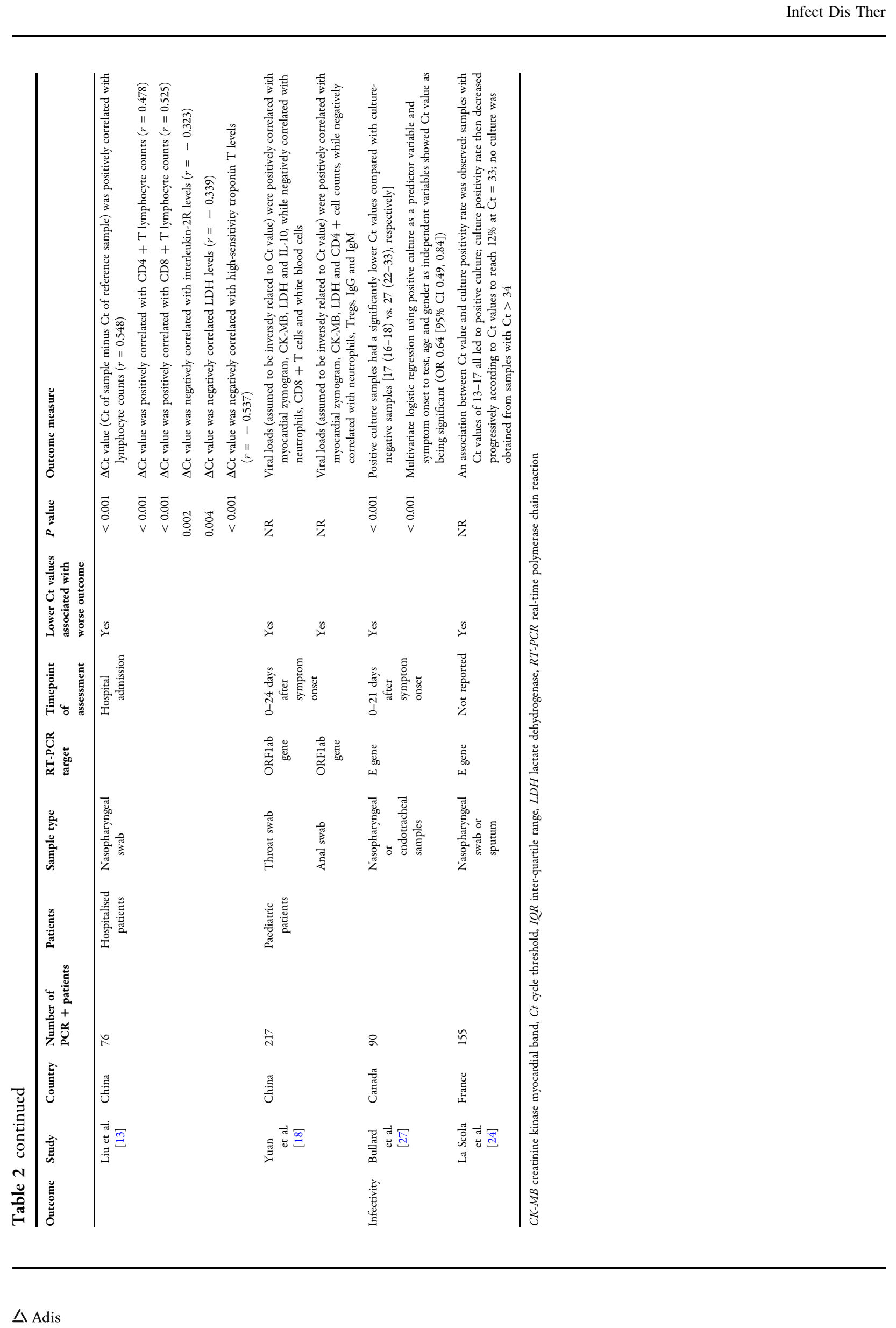


nasal swabs of asymptomatic and symptomatic patients was not statistically different (median $4.7 \log _{10}$ copies $/ \mathrm{ml}$ vs. $5.0 \log _{10}$ copies $/ \mathrm{ml}$; $p=0.51$ ) [33].

Ct values were found to correlate with a number of clinical markers. Lower $\mathrm{Ct}$ values were associated with elevated LDH levels in all four studies in which it was assessed, which is consistent with reports that elevated LDH can act as an indicator of poor prognosis in patients with COVID-19 [34, 35]. Increased LDH reflects tissue destruction and in interstitial pulmonary fibrosis is seen as an important prognostic marker for lung injury [36]. Lower Ct values were associated with lower lymphocyte levels in all three studies in which they were assessed, which is consistent with reports that lymphopaenia could act as a predictor of higher disease severity in patients with COVID-19 $[35,37]$. Similarly, correlation of Ct values was also seen with high-sensitivity troponin I, which has been suggested as a marker of COVID-19 disease progression and mortality [35].

Both studies that investigated the correlation between SARS-CoV-2 Ct values and infectivity showed that samples with higher Ct values had lower culture positivity. It has been shown that following resolution of COVID-19 symptoms, people can have prolonged positive SARS-CoV-2 real-time PCR results for several weeks [38] and, at late time points, $\mathrm{Ct}$ values are often very high representing low copies of viral RNA [20]. Therefore, as suggested previously [4], considering Ct values in conjunction with the clinical context of patients may help in patient management decisions such as the need for isolation, use of PPE and testing resources.

To the best of our knowledge, this is the first report to systematically assess the globally available literature data relating to the predictive value of SARS-CoV-2 Ct values; however, it is associated with a number of limitations. The majority of the studies included in this review contained a relatively small number of patients; only four studies included $>100$ patients with COVID-19 [11, 15, 18, 24]. The viral load of SARS-CoV-2 is known to vary during the course of infection [10,11, 13, 19, 20, 39-42]. The time from onset of symptoms to sampling varied between studies and in most of the included studies, varied between patients. Time from onset of symptoms was included as an independent variable in only one of the analyses presented [27] and therefore this may be a confounding factor in many of the studies reported. The type of sample used varied between studies. Sample type is known to affect the $\mathrm{Ct}$ values and detected viral load $[20,40]$, and therefore this may have affected results. The variability within and between the included studies is not consistent with previously reported considerations regarding variability around factors (sample type, workflow, assay) involved in robust viral load measurement using RT-PCR [3]. Reproducible experimental layouts to assess viral load from patient samples are key to establish any correlation to patient outcome.

\section{CONCLUSIONS}

Reporting of qualitative SARS-CoV-2 test results as positive or negative is sufficient for diagnosis, but the totality of currently available data indicates that the reporting of $\mathrm{Ct}$ values may offer benefit to clinicians in making clinical and patient-management decisions for patients with COVID-19 as well as guide infection control, public health and occupational health decisions. However, additional data and prospective studies are required to support this.

\section{ACKNOWLEDGEMENTS}

Funding. This study was funded by Qiagen Manchester Ltd, who also funded the journal's Rapid Service Fees.

Medical Writing, Editorial and Other Assistance. The authors would like to acknowledge Tom Hudson, PhD, and Sarah Rossall, PhD, of Ashfield Healthcare Communications, part of UDG Healthcare plc, for assistance with literature screening that was funded by Qiagen Manchester Ltd. 
Authorship. All named authors meet the International Committee of Medical Journal Editors (ICMJE) criteria for authorship for this article, take responsibility for the integrity of the work as a whole, and have given their approval for this version to be published. All authors contributed to data analysis, data interpretation and writing of this report.

Disclosures. Sonia Rao is an employee of QIAGEN Inc. Davide Manissero is an employee of QIAGEN Manchester Ltd. Victoria Steele is an employee of Ashfield Healthcare Communications, part of UDG Healthcare plc, which received funding from Qiagen Manchester Ltd to conduct the study. Josep Pareja is an employee of STAT-Dx Life, a QIAGEN company.

Compliance with Ethics Guidelines. This article is based on previously conducted studies and does not contain any studies with human participants or animals performed by any of the authors.

Open Access. This article is licensed under a Creative Commons Attribution-NonCommercial 4.0 International License, which permits any non-commercial use, sharing, adaptation, distribution and reproduction in any medium or format, as long as you give appropriate credit to the original author(s) and the source, provide a link to the Creative Commons licence, and indicate if changes were made. The images or other third party material in this article are included in the article's Creative Commons licence, unless indicated otherwise in a credit line to the material. If material is not included in the article's Creative Commons licence and your intended use is not permitted by statutory regulation or exceeds the permitted use, you will need to obtain permission directly from the copyright holder. To view a copy of this licence, visit http://creativecommons.org/ licenses/by-nc/4.0/.

\section{REFERENCES}

1. Poletti P, Tirani M, Cereda D, et al. Probability of symptoms and critical disease after SARSCoV-2 infection. arXiv:2006.08471.

2. Tang Y-W, Schmitz JE, Persing DH, Stratton CW. Laboratory diagnosis of COVID-19: current issues and challenges. J Clin Microbiol. 2020;58(6): e00512-e520.

3. Bustin SA, Mueller R. Real-time reverse transcription PCR (qRT-PCR) and its potential use in clinical diagnosis. Clin Sci (Lond). 2005;109:365-79.

4. Tom MR, Mina MJ. To interpret the SARS-CoV-2 test, consider the cycle threshold calue. Clin Infect Dis. 2020;ciaa619.

5. Joynt $\mathrm{GM}, \mathrm{Wu} \mathrm{WK}$. Understanding COVID-19: what does viral RNA load really mean? Lancet Infect Dis. 2020;20:635-6.

6. Geddes L. Puzzle over viral load. New Sci. 2020;245: 8.

7. Cheng VC, Hung IF, Tang BS, et al. Viral replication in the nasopharynx is associated with diarrhea in patients with severe acute respiratory syndrome. Clin Infect Dis. 2004;38:467-75.

8. Ng EK, Hui DS, Allen Chan KC, et al. Quantitative analysis and prognostic implication of SARS coronavirus RNA in the plasma and serum of patients with severe acute respiratory syndrome. Clin Chem. 2003;49:1976-80.

9. Chu CM, Poon LLM, Cheng VCC, et al. Initial viral load and the outcomes of SARS. CMAJ. 2004;171: 1349-52.

10. He XL, Lau EHY, Wu P, et al. Temporal dynamics in viral shedding and transmissibility of COVID-19. Nat Med. 2020;26:672-5.

11. Huang JTR, Ran RX, Lv ZH, et al. Chronological changes of viral shedding in adult inpatients with COVID-19 in Wuhan, China. Clin Infect Dis. 2020; ciaa631.

12. Liu Y, Yan LM, Wan L, et al. Viral dynamics in mild and severe cases of COVID-19. Lancet Infect Dis. 2020;20:656-7.

13. Liu YL, Liao W, Wan L, Xiang T, Zhang W. Correlation between relative nasopharyngeal virus RNA load and lymphocyte count disease severity in patients with COVID-19. Viral Immunol. 2020. https://doi.org/10.1089/vim.2020.0062. 
14. Liu YY, Yang Y, Zhang C, et al. Clinical and biochemical indexes from 2019-nCoV infected patients linked to viral loads and lung injury. Sci China Life Sci. 2020;63:364-74.

15. Shi FW, Wu T, Zhu X, et al. Association of viral load with serum biomakers among COVID-19 cases. Virology. 2020;546:122-6.

16. Xia XYW, Wu J, Liu HL, Xia H, Jia B, Huang WX. Epidemiological and initial clinical characteristics of patients with family aggregation of COVID-19. J Clin Virol. 2020;127:104360.

17. Yu XS, Sun S, Shi Y, Wang H, Zhao R, Sheng J. SARSCoV-2 viral load in sputum correlates with risk of COVID-19 progression. Crit Care. 2020;24:170.

18. Yuan CZ, Zhu H, Yang Y, et al. Viral loads in throat and anal swabs in children infected with SARS-CoV2. Emergin Microbe Infect. 2020;9:1-17.

19. Zheng SF, Fan J, Yu F, et al. Viral load dynamics and disease severity in patients infected with SARS-CoV2 in Zhejiang province, China, January-March 2020: retrospective cohort study. BMJ. 2020;369: $\mathrm{m} 1443$.

20. Zou LR, Ruan F, Huang M, Liang L, et al. SARS-CoV2 viral load in upper respiratory specimens of infected patients. N Engl J Med. 2020;382:1177-9.

21. To KKT, Tsang OT, Leung WS, et al. Temporal profiles of viral load in posterior oropharyngeal saliva samples and serum antibody responses during infection by SARS-CoV-2: an observational cohort study. Lancet Infect Dis. 2020;20:565-74.

22. Azzi LC, Carcano G, Gianfagna F, et al. Saliva is a reliable tool to detect SARS-CoV-2. J Infect. 2020. https://doi.org/10.1016/j.jinf.2020.04.005. Epub ahead of print.

23. Schwierzeck VK, König JC, Kühn J, et al. First reported nosocomial outbreak of severe acute respiratory syndrome coronavirus 2 (SARS-CoV-2) in a pediatric dialysis unit. Clin Infect Dis. 2020;ciaa491

24. La Scola BLB, Le Bideau M, Andreani J, et al. Viral RNA load as determined by cell culture as a management tool for discharge of SARS-CoV-2 patients from infectious disease wards. Eur J Clin Microbiol Infect Dis. 2020;39:1059-61.

25. Arons MM, Hatfield KM, Reddy SC, et al. Presymptomatic SARS-CoV-2 infections and transmission in a skilled nursing facility. New Engl J Med. 2020;382: 2081-90.

26. Kimball AH, Hatfield KM, Arons M, et al. Asymptomatic and presymptomatic SARS-CoV-2 infections in residents of a long-term care skilled nursing facility - King County, Washington, March 2020. MMWR Morb Mortal Wkly Rep. 2020;69:377-81.

27. Bullard JD, Dust K, Funk D, et al. Predicting infectious SARS-CoV-2 from diagnostic samples. Clin Infect Dis 2020; ciaa638.

28. Aquino-Jarquin G. The raw Ct values from RT-PCR detection are not viral load quantitation units. Clin Infect Dis. 2020; ciaa830.

29. Feikin DR, Alraddadi B, Qutub M, et al. Association of higher MERS-CoV virus load with severe disease and death, Saudi Arabia, 2014. Emerg Infect Dis. 2015;21:2029-35.

30. Lee N, Chan PK, Hui DS, et al. Viral loads and duration of viral shedding in adult patients hospitalized with influenza. J Infect Dis. 2009;200: 492-500.

31. Wishaupt JO, Ploeg TV, Smeets LC, Groot R, Versteegh FG, Hartwig NG. Pitfalls in interpretation of CT-values of RT-PCR in children with acute respiratory tract infections. J Clin Virol. 2017;90:1-6.

32. Feikin DR, Fu W, Park DE, et al. Is higher viral load in the upper respiratory tract associated with severe pneumonia? Findings from the PERCH study. Clin Infect Dis. 2017;64:S337-S34646.

33. Cereda D, Tirani M, Rovida F, et al. The early phase of the COVID-19 outbreak in Lombardy, Italy. arXiv:2003.09320.

34. Yan L, Zhang H-T, Goncalves J, et al. An interpretable mortality prediction model for COVID-19 patients. Nat Mach Intelligence. 2020;2:283-8.

35. Kermali M, Khalsa RK, Pillai K, Ismail Z, Harky A. The role of biomarkers in diagnosis of COVID-19A systematic review. Life Sci. 2020;254:117788.

36. Kishaba T, Tamaki H, Shimaoka Y, Fukuyama H, Yamashiro S. Staging of acute exacerbation in patients with idiopathic pulmonary fibrosis. Lung. 2014;192:141-9.

37. Tan L, Wang Q, Zhang D, et al. Lymphopenia predicts disease severity of COVID-19: a descriptive and predictive study. Signal Transduct Target Ther. 2020;5:33.

38. Xiao AT, Tong YX, Zhang S. Profile of RT-PCR for SARS-CoV-2: a preliminary study from 56 COVID19 patients. Clin Infect Dis. 2020; ciaa460.

39. Huang YC, Chen S, Yang Z, et al. SARS-CoV-2 viral load in clinical samples of critically ill patients. Am J Respir Crit Care Med. 2020;201:1435-8. 
40. Pan YZ, Zhang D, Yang P, Poon LLM, Wang Q. Viral load of SARS-CoV-2 in clinical samples. Lancet Infect Dis. 2020;20:411-2.

41. Yu FY, Yan L, Wang N, Yang S, Wang L, Tang Y, et al. Quantitative detection and viral load analysis of SARS-CoV-2 in infected patients. Clin Infect Dis. 2020; ciaa345.

42. Wölfel RC, Corman VM, Guggemos W, et al. Virological assessment of hospitalized patients with COVID-2019. Nature. 2020;581:465-9. 